\title{
Fresh Water
}

\author{
Janet G. Hering
}

L et's close our eyes and think of the words 'fresh water'. What images come to mind? Perhaps we think of a gentle spring rain that nourishes wildflowers and newly planted crops. We may envision a clear lake with fish schooling just under the surface, or a rushing stream with migrating salmon leaping from the water. In wealthier countries or regions, we may think of filling a glass of water from the tap, or of our morning shower, often without realizing what a privilege it is to have safe water delivered reliably to our homes. We may also recall water being used to fight fires or for irrigation, transportation and hydropower. Negative images may also come to mind, such as the environmental devastation associated with water pollution or its diversion for agriculture or hydropower. Or we might think of the torrential downpours that cause flooding and the loss of human life and property. These examples illustrate that people across the globe can experience fresh water in vastly different ways.

Throughout history, water has always been of central importance for human welfare. Each person needs about $80 \mathrm{~L}$ of water per day for drinking, cooking and hygiene (30,000 $\mathrm{L}$ per year) and about a factor of forty more (1.2 million L per year) if dietary needs are included. Because of these essential requirements for water and the importance of natural waterbodies and watercourses for fishing, transportation and even defense, the geography 
of major rivers, deltas and coastlines has profoundly influenced the patterns of human settlement. Dating back to antiquity, great civilizations have also shaped the landscape of water features (or waterscapes) through diversions and damming of rivers, and the draining of wetlands. Some of these changes have left visible reminders, such as the ancient Roman aqueducts. But in the absence of such artifacts, we tend to forget how massive our influence has been. For example, few citizens of the United States realize that six States have lost over $85 \%$ of their wetlands. In Europe, it is impossible even to estimate such losses. In our modern world, the altered waterscape appears to us as natural.

Despite the successes of ancient civilizations in managing water supply and waste management, industrialization and urban growth in both Europe and North America were accompanied by severe outbreaks of water-borne disease. As described by David Sedlak in his book Water 4.0: The Past, Present, and Future of the World's Most Vital Resource, cholera and typhoid epidemics were common in the nineteenth and early twentieth centuries. ${ }^{1} \mathrm{~A}$ major cholera outbreak in London in 1848 was famously traced to a well contaminated by sewage discharges to the River Thames. A series of improvements in water supply (including the protection of water sources, sand filtration and chlorination) led to massive improvements in public health in industrialized countries in the early- to mid-1900s.

At the time of the first Earth Day in 1970, the benefits of safe drinking water and improved public health were mainly taken for granted in wealthy countries. But these societies had failed to address the visible and extreme pollution of rivers and lakes resulting from the discharge of industrial wastes and inadequately treated sewage. Oil and industrial waste on the Cuyahoga River in Cleveland, Ohio, famously caught fire - not for the first time - in 1969. That same year, Lake Erie was pronounced 'dead' by major news agencies. ${ }^{2}$ Massive fish kills resulted from both industrial pollution and introduction of nutrients (eutrophication) that created a 'dead zone' with insufficient oxygen for fish. These drastic environmental impacts motivated much of the activism of the first Earth Day as well as the establishment of the US Environmental Protection Agency (EPA). The US Clean Water Act of 1972 set the stage for massive improvements in environmental protection, including widespread upgrading of wastewater treatment. The impacts of industry on water quality were also a concern in Europe. In 1986, a fire at a chemical storage facility in Basel near 
the Swiss border shocked Europe with severe contamination of the Rhine River and a complete die-off of fish along the entire length of the river. As in the US, these events led to national and international legislation and agreements to curtail pollution and monitor water quality, as detailed in Frank Dunnivant's book Environmental Success Stories: Solving Major Ecological Problems and Confronting Climate Change. ${ }^{3}$

The first Earth Day did not need to focus on access to safe drinking water and adequate sanitation, since these problems had already been solved in industrialized countries. The situation was, however, quite different in low- and middle-income countries (LMICs). To improve access to safe drinking water and adequate sanitation, the United Nations adopted the Millennium Development Goals (MDGs) in 2000, ${ }^{4}$ recognized a universal human right to water and sanitation in 2010, and adopted the Sustainable Development Goals (SDGs) in 2015. ${ }^{5}$ As a result of these international commitments, between 2000 and 2017, the proportion of the global population using safely managed services increased from $28 \%$ to $45 \%$ for sanitation, and from $61 \%$ to $71 \%$ for drinking water. Even in the Least Developed Countries, access to safely managed drinking water increased from $25 \%$ to $35 \% .{ }^{6}$

The SDGs challenge the nations of the world to address human development and the environment in a concerted manner. The theme of the 2019 UNEnvironment report - Global Environment Outlook (GEO) 6: Healthy Planet, Healthy People ${ }^{7}$ - highlights our reliance on ecosystem services. The recognition of the vital importance of fresh water ecosystems, which are among the planet's most biodiverse habitats, has led some nations, notably Ecuador, India, South Africa and New Zealand, to formalize the rights of the environment to water by limiting diversions of water, requiring the maintenance of minimum flow regimes, or even by conferring the legal status of persons on rivers. Notwithstanding these developments, the integrity and function of fresh water ecosystems are subject to increasing pressures, which derive from population growth, urbanization, water pollution, unsustainable development and climate change. The GEO-6 report clearly concludes that the world is not on track to achieve the environmental SDGs.

Achieving the SDGs will require that we find balances between our direct uses of water and the maintenance of aquatic ecosystem function. Balanced solutions will vary depending on local contexts and national priorities. Ideally, any solutions would 
avoid unanticipated consequences of narrowly focused measures and take advantage of synergies among the different SDGs. For water, SDG 6 ('Ensure availability and sustainable management of water and sanitation for all') is an obvious focus for investment and action. But protecting and improving fresh water quality are also incorporated in the targets to reduce the environmental impacts of cities (SDG 11), reduce marine pollution from land-based activities (SDG 14) and to conserve and restore freshwater ecosystems and their use (SDG 15). ${ }^{8}$ Thus, progress toward these targets would also help to achieve SDG 6.

W

e can take the successes in improving water quality in industrialized countries since the first Earth Day as examples of effective strategies and measures. But we must be aware that the successful strategies of water management developed in industrialized countries depended heavily on prior infrastructure investments, which also caused ecological harm. These successful strategies also reflected climatic conditions that are quite different from those in countries facing water insecurity today. In addition, many of today's water insecure countries are experiencing population growth and increasing urbanization and have not yet fully developed their industrial base.

One example that is both motivating and cautionary is the past success of industrialized countries in providing safe water supply and sanitation - the central objective of SDG 6 . This success is the basis for today's conventional paradigm for water and wastewater management, which reflects the climate, geography and historical development of Western Europe and North America. In this paradigm, water is used to transport waste, and the rapid conveyance of storm water away from urban areas is prioritized to prevent flooding. Systems are highly centralized, and water supply and wastewater are strictly separated.

In water-scarce regions of LMICs, however, using water for waste conveyance is not a practical use of a scarce resource, and the required investment in sewers would be prohibitively expensive. An attractive alternative is to reclaim water, energy and nutrients from wastewater (or from fecal sludge). This approach, which relaxes the strict distinction between water and wastewater, is also being taken up by industrialized countries as they 
move toward circular economies and replace aging infrastructure. Looking to the future, it seems that the fully centralized model of industrialized countries may not be the dominant, much less the only, way forward.

Infrastructure investment provides another example where caution should be exercised in emulating the past successes of industrialized countries. Past infrastructure investments for water conveyance and storage increased water security and, through hydropower production, energy security. Today, LMICs face massive infrastructure deficits, which call for trillion-dollar investments. ${ }^{9}$ Thousands of major hydropower dams, with capacities of at least $1 \mathrm{MW}$, are in the planning or construction phase with most sited in LMICs. ${ }^{10}$ Future infrastructure construction and planning should take into account past experiences with the ecological and social consequences of such projects as well as projections regarding future climate that might compromise intended benefits. LMICs that heed the lessons learned regarding loss of ecosystem services of watercourses and the social and ecological impacts of land lost to reservoirs may choose to pursue alternative energy production through renewable wind and solar energy. ${ }^{11}$

$\mathrm{T}$ oday, water pollution poses different challenges for industrialized countries and LMICs. Despite the past successes of industrialized countries in controlling industrial pollution and upgrading municipal wastewater treatment plants, not all problems have been solved. Some of the remaining challenges for these wealthy countries derive from the widespread use of pharmaceuticals and personal care products that are poorly removed in conventional wastewater treatment. ${ }^{12}$ Micro-plastics also pass through wastewater treatment plants and are released into the environment with the effluent. ${ }^{13}$ This problem is partly addressed by recent legislation prohibiting the use of micro-plastics in some consumer products, but plastic microfibers are released whenever synthetic fabrics are washed. Other challenges arise from diffuse pollution, which is most often associated with agriculture. Fertilizers and plant protection products (PPPs), including pesticides, herbicides and fungicides, are used in agriculture and can contaminate groundwater as well as inland and coastal waters. ${ }^{14}$ PPPs are often found in groundwater and surface fresh water at concentrations that exceed risk levels for sensitive aquatic species. The runoff of 
agricultural fertilizers into coastal waters has resulted in the formation of oxygen-deficient dead zones extending over more than $10,000 \mathrm{~km}^{2}$.

In some LMICs, point-source pollution is accompanying rapid industrial development. This is a particular concern with the expansion of chemical and pharmaceutical production in the Asia Pacific. ${ }^{15}$ In rapidly growing economies, regulatory controls on the discharge of industrial effluents are often inadequately enforced. Import of single-use and poorly recyclable plastics from industrialized countries, ostensibly for recycling, has led to massive accumulation of plastics in both fresh waters and the ocean. As in industrialized countries, agriculture also accounts for much of the diffuse pollution in LMICs. Worldwide, both the highest and lowest uses of PPPs are in LMICs with the highest application rates of pesticides in Latin America and the lowest in sub-Saharan Africa. Fertilizer application is also lowest in sub-Saharan Africa resulting in depressed crop yields.

The diverse challenges related to water use across the globe call for locally-appropriate, sustainable balances between meeting direct human needs for water and preserving the capacity of the water environment to provide ecosystem services. Location is critical because water issues arise from local conditions (such as climate and past infrastructure investment) and viable solutions to water issues can only be implemented by people and institutions with local authority and responsibility. ${ }^{16}$ At the same time, demands and pressures on water resources in a specific location often reflect consumption patterns in distant countries importing embedded (or virtual) water, especially in the form of agricultural products. In Switzerland, for example, over $80 \%$ of the national water footprint derives from imported goods and services. ${ }^{17}$ The inherent linkages between water, food and energy pose challenges to conventional, sector-based approaches to resource management, but also offer opportunities to leverage synergies. Water use in agriculture, for example, could be reduced by application of sensors and precision technologies to avoid excessive irrigation, re-use of treated wastewater and adoption of diets that include less meat.

Progressing toward a circular economy will be a key element in decoupling human well-being from resource exploitation, including unsustainable demands on fresh water. ${ }^{18}$ Recovery of the nutrients nitrogen and phosphorus from human excreta could provide renewable and less energy-intensive fertilizers for agriculture. Separated plumbing systems 
for greywater(i.e., wastewater not contaminated with fecal waste) could allow in-home re-use, substantially decreasing the demand on the water supply to the household. Decentralized systems for water and wastewater could reduce the need for water distribution systems and sewers with their associated costs and often-substantial loss of water through leaks.

There will not be a 'one-size-fits-all' solution to meet the water-related challenges of the SDGs. We will need to work cooperatively to develop a shared portfolio of approaches that can be adapted for local conditions. ${ }^{19}$ Cooperation must extend across sectors and include the co-production of knowledge by actors with different expertise, backgrounds, experience and responsibility. Advances in technology must be effectively harnessed, including new sensors, data technologies and real-time process control that can dramatically improve water efficiency. Open access to data will be critical to maximizing water efficiency and reducing environmental harm. At the same time, data platforms can raise public awareness of the importance and vulnerability of fresh water systems and encourage citizen engagement. More generally, open access to scientific knowledge could promote evidence-based and participatory water management. ${ }^{20}$

To realize the SDGs, we can take the attributes of water as a guide. Water flows around obstacles - SDG implementation must also be adaptive and appropriate to local contexts. Over time, water can wear away the hardest stone - we must also be persistent. Water has great power that can be destructive but can also be harnessed productively - as individuals and collectively, we too have the power to transform our societies. The Sustainable Development Goals demand nothing less.

\section{Endnotes}

1. D. Sedlak, Water 4.0: The Past, Present, and Future of the World's Most Vital Resource, New Haven: Yale University Press, 2014, 41-62.

2. See 'Oceans 2020' by David M. Karl in this volume.

3. F. Dunnivant, Environmental Success Stories: Solving Major Ecological Problems and Confronting Climate Change, New York: Columbia University Press, 2017, 129-39, https://doi.org/10.7312/dunn17918 
4. Available at https://www.who.int/topics/millennium_development_goals/about/en/

5. Available at https://sustainabledevelopment.un.org/?menu=1300

6. UNICEF and WHO, Progress on Household Drinking Water, Sanitation and Hygiene 2000-2017: Special Focus on Inequalities, ed. R. Steele, New York: UNICEF and WHO, 2019, https://washdata.org/sites/ default/files/documents/reports/2019-07/jmp-2019-wash-households.pdf

7. UNEP, Global Environment Outlook - GEO-6: Healthy Planet, Healthy People, ed. P. Ekins, J. Gupta and P. Boileau, Nairobi: UNEP, 2019, https://doi.org/10.1017/9781108627146, https://www. unenvironment.org/resources/global-environment-outlook-6

8. J. Sachs, G. Schmidt-Trabu, G. Kroll, G. Lafortune and G. Fuller, Sustainable Development Report 2019: Transformations to Achieve the Sustainable Development Goals, New York: Bertelsmann Stiftung \& Sustainable Development Solutions Network, 2019, https://www.bertelsmann-stiftung.de/en/ publications/publication/did/sustainable-development-report-2019/

9. The World Bank, Rebalancing, Growth, and Development: An Interconnected Agenda, Washington, DC: The World Bank, 2011, https://siteresources.worldbank.org/INTWDRS/Resources/WDR2011_ Full_Text.pdf

10. C. Zarfl, A. E. Lumsdon, J. Berlekamp, L. Tydecks and K. Tockner, 'A global boom in hydropower dam construction', Aquatic Sciences, 2015, 77, 161-70, https://doi.org/10.1007/s00027-014-0377-0

11. J. Opperman, J. Hartmann, M. Lambrides, J. P. Carvallo, E. Chapin, S. Baruch-Mordo, B. Eyler, M. Goichot, J. Harou, J. Hepp et al., Connected and Flowing: A Renewable Future for Rivers, Climate and People, Washington, DC: WWF and The Nature Conservancy, 2019, http://d2ouvy59p0dg6k. cloudfront.net/downloads/connected_and_flowing__wwf_tnc_report__5.pdf

12. See also 'The Global Chemical Experiment' by Elsie Sunderland and Charlotte C. Wagner in this volume.

13. See also 'Earth and Plastic' by Roland Geyer in this volume.

14. J. Mateo-Sagasta, S. M. Zadeh and H. Turral (eds.), More People, More Food, Worse Water? A Global Review of Water Pollution from Agriculture, Rome: FAO and IMWI, 2018, http://www.fao.org/3/ ca0146en/CA0146EN.pdf

15. UNEP, GEO-6 for Industry in Asia-Pacific, Nairobi: UNEP, 2019, https://www.unenvironment.org/ resources/report/global-environment-outlook-6-industry-asia-pacific

16. J. G. Hering, D. Sedlak, C. Tortajada, A. K. Biswas, C. Niwagaba and T. Breu, 'Local perspectives on water', Science, 2015, 349, 479-80, https://doi.org/10.1126/science.aac5902 
17. WWF, The Swiss Water Footprint Report, Switzerland:WWF, 2012, https://www.eda.admin.ch/dam/ deza/en/documents/publikationen/Diverses/209748-wasser-fussabdruck-schweiz_EN.pdf

18. T. A. Larsen, S. Hoffmann, C. Luthi, B. Truffer and M. Maurer, 'Emerging solutions to the water challenges of an urbanizing world', Science, 2016, 352, 928-33, https://doi.org/10.1126/science. $\operatorname{aad} 8641$

19. J. G. Hering, 'Water: The environmental, technological and societal complexity of a simple substance', in Encyclopedia of Water: Science, Technology, and Society, ed. P. Maurice, New York: John Wiley \& Sons, 2019, 1-9, https://doi.org/10.1002/9781119300762.wsts0038

20. WWF-US, Free Flowing Rivers, http://freeflowingriver.org/about; Earthwatch Institute, FreshWaterWatch, https://freshwaterwatch.thewaterhub.org/content/citizen-science 